\title{
ANÁLISE ESPAÇO-TEMPORAL DA DISTRIBUIÇÃO DE SEDIMENTOS NOS RIOS AGUAPEÍ E PEIXE, OESTE PAULISTA
}

\author{
Aline Aparecida dos Santos ${ }^{1}$ \\ Jhonatan Laszlo Manoel $^{2}$ \\ Paulo Cesar Rocha ${ }^{3}$
}

RESUMO: O presente trabalho teve o objetivo realizar uma análise da distribuição granulométrica dos sedimentos de leito nos Rios Aguapeí e Peixe, discutindo os resultados a partir de uma perspectiva espaçotemporal. As Bacias Hidrográficas dos Rios Aguapeí e Peixe estão localizadas no oeste do Estado de São Paulo, compreendendo as regiões administrativas de Marília e Presidente Prudente. Para a realização do estudo foram coletadas amostras em duas seções transversais dos Rios Aguapeí e do Peixe, com pontos de amostragem localizados a alto e a baixo curso dos canais. As amostras foram obtidas nos meses de dezembro de 2011 e junho de 2012, em concordância com o regime sazonal abrangendo um período pré e pós águas altas. A partir da análise dos dados de frequência, verificou-se que nos Rio Aguapeí e Peixe houve um predomínio das classes granulométricas de areia média e areia fina nas seções e períodos amostrados. E geral a distribuição dos materiais mantiveram um padrão de distribuição no período considerado pós águas altas, no mês de junho, enquanto é possível observar que no mês de dezembro, período pré águas altas, há maior variação na distribuição, principalmente no sentindo montante a jusante do canal.

Palavras-chave: Hidrossedimentologia. Dinâmica Fluvial. Bacia Hidrográfica.

\footnotetext{
${ }^{1}$ Graduanda em Geografia, FCT/UNESP. E-mail: aline.ap.as@hotmail.com.

${ }^{2}$ Graduando em Geografia, FCT/UNESP. E-mail: jho896@hotmail.com.

${ }^{3}$ Prof $^{\circ}$. Dr. Do Departamento de Geografia, FCT/UNESP. E-mail: pcrocha@fct.unesp.br.
} 


\section{INTRODUÇÃO}

O presente trabalho teve como objetivo realizar uma análise da distribuição granulométrica dos sedimentos de leito em trechos dos Rios Aguapeí e Peixe, discutindo os resultados a partir de uma perspectiva espaço-temporal, utilizando medidas estatísticas para análise.

Em busca do desenvolvimento da sociedade, o homem intensificou no decorrer dos anos suas ações sobre o meio natural, apropriando-se inadequadamente dos recursos naturais. Tal intervenção provocou uma série de danos a natureza, modificando os espaços naturais e construindo novas paisagens. Em contrapartida, este desenvolvimento trouxe à tona preocupações com a degradação imposta ao meio ambiente, sendo o ponto de partida para as discussões referentes à preservação ambiental e a minimização destes impactos.

Como ressalta Ross (1998), nas relações humanas com o meio natural, a natureza é vista como um recurso, como um suporte para a sobrevivência humana. Neste sentido, através do uso e ocupação do solo e da apropriação dos recursos hídricos, a intervenção humana em bacias hidrográficas tem resultado em mudanças na dinâmica dos canais fluviais, interferindo em seus ecossistemas em diferentes escalas.

Diante disso, a Geomorfologia Fluvial contribui a partir de conceitos e metodologias, servindo como suporte para pesquisas ligadas a bacia hidrográfica e os cursos d'água. Cunha (2001), destaca que a Geomorfologia Fluvial adota uma perspectiva interdisciplinar a partir da década de 1970, agregando outras áreas de conhecimento em seus trabalhos, tal como Pedologia, Hidrologia e Ecologia, passando a preocupar-se com as modificações no ambiente fluvial, decorrentes da atuação do homem.

Desta maneira, pesquisas voltadas aos canais fluviais e dos processos que atuam em seus limites tornam-se instrumentos necessários ao planejamento e gestão dos recursos hídricos, além de suporte para projetos de recuperação, quando vistas como indicativos de mudanças nas características morfológicas e hidráulicas do rio bem como do estado da água. 


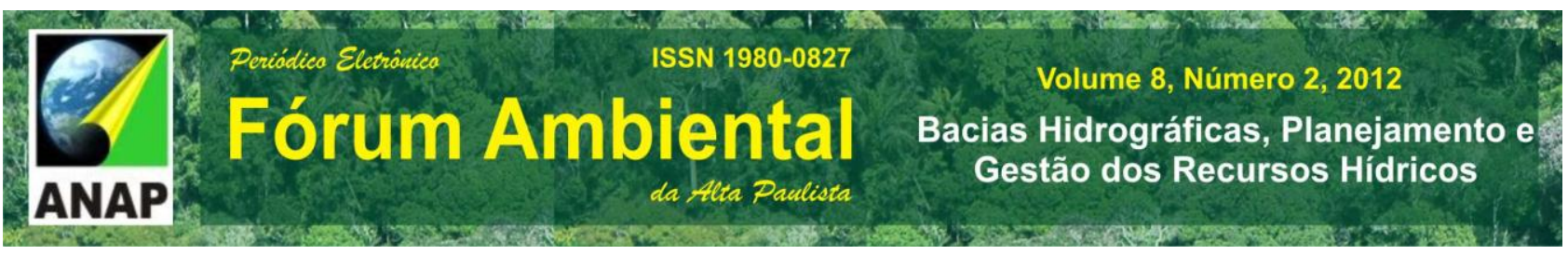

\section{DISCUSSÃO TEÓRICA}

Segundo Botelho e Silva (2007), em referência a Botelho e Corato (2001), a maior parte de estudos com temas ligados a erosão, manejo e conservação do solo e da água e planejamento ambiental, adota a bacia hidrográfica como unidade de análise. Nascimento e Villaça (2008) destacam que em uma bacia hidrográfica os processos de circulação de matéria e de energia que nela se operam envolvem os canais fluviais e planícies de inundação assim como as vertentes, nas quais os processos internos são de suma importância. Sob esta perspectiva, a bacia hidrográfica como base torna-se um instrumento ideal para uma análise integrada do meio ambiente, visto que "entendida como célula básica de análise ambiental, a bacia hidrográfica permite conhecer e avaliar seus diversos componentes e os processos e interações que nela ocorrem" (BOTELHO \& SILVA, 2007, p. 154).

De acordo com Suguio (1979), a bacia hidrográfica ou bacia de drenagem constituise em um conjunto de canais de escoamento interligados (drenagem fluvial), podendo ser definida como área abrangida por um rio ou sistema fluvial composto por um curso principal e seus afluentes. O fluxo fluvial compreende a descarga líquida e o material transportado pelo rio, este constituído por carga dissolvida, em suspensão ou do leito.

A dinâmica do escoamento, no que se refere à perspectiva geomorfológica, ganha significância na atuação exercida pela água sobre os sedimentos do leito fluvial, no transporte dos sedimentos, nos mecanismos deposicionais e na esculturação da topografia do leito (CHRISTOFOLETTI, 1981, pag. 01).

Nesta perspectiva, Novo (2008), ressalta que os rios são poderosos agentes geomorfológicos, capazes de erodir, transportar e depositar sedimentos. Tais processos são interdependentes, que em sua relação constituem uma dinâmica dentro da bacia de drenagem, exercendo influência no ambiente fluvial do ponto de vista biótico e abiótico.

De acordo com Silva, Schulz \& Camargo (2004), os sedimentos que chegam aos cursos d'água possuem diferentes granulometrias e sofrem um processo de transporte variado conforme as condições locais e de escoamento. A carga de fundo compreende partículas de granulometria maior, como cascalhos, areia ou fragmentos de rocha, que em decorrência de sua dimensão são transportados por saltação ou rolamento. 


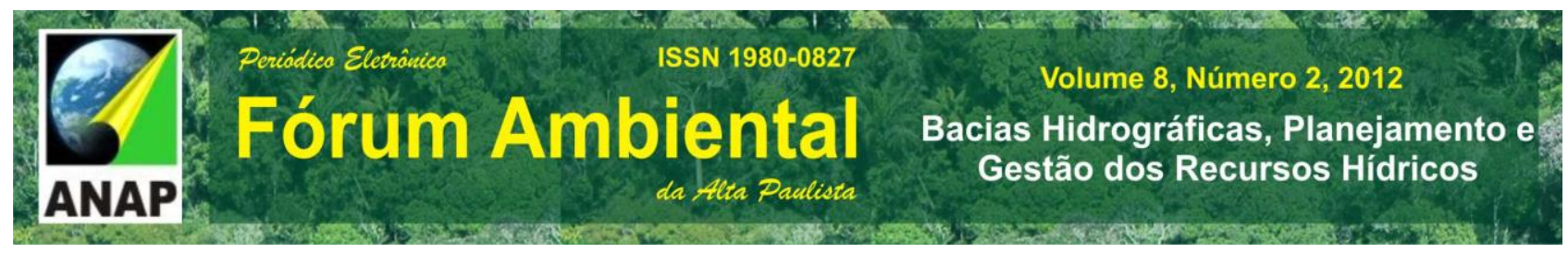

A origem do material e o seu carregamento para os cursos d'águas recebem influência da quantidade e distribuição das precipitações, a estrutura geológica, as condições topográficas e a cobertura vegetal da bacia hidrográfica, uma vez que esse material é fornecido pela sua remoção das vertentes e da ação erosiva da água nas margens e fundo do canal fluvial (CHRISTOFOLETTI, 1981). Já a distribuição do material está associada à relação entre a granulometria das partículas e as características do fluxo fluvial.

Segundo Bigarella e Suguio (1979), a descarga líquida de um canal pode ser expressa pela equação $Q=A \times V$. Esta equação demonstra "que a vazão (Q) depende da área (A) da secção do canal e da velocidade (V) do fluxo" (BIGARELLA \& SUGUIO, 1979, p. 29). Tal relação determina o tamanho máximo do material que pode ser transportado (competência do rio) e o volume de carga que pode ser transportado (capacidade do rio). Sendo assim, a baixas velocidades a água transporta partículas muito finas (carga em suspensão) por fluxo laminar, enquanto em maior velocidade, o que caracteriza um fluxo turbulento, partículas maiores são transportadas.

A velocidade da água em um canal fluvial depende de fatores como a declividade do perfil longitudinal, volume das águas, formas da secção transversal, rugosidade do leito e viscosidade da água (CUNHA, 2001). As variáveis vazão e velocidade, bem como a largura, profundidade, a rugosidade do canal e a concentração e granulometria de sedimentos constituem a geometria hidráulica de um canal fluvial. A geometria hidráulica refere-se ao estudo das características geométricas e de composição dos canais fluviais, consideradas através das relações que se estabelecem no perfil transversal (CHRISTOFOLETTI, 1981, p. 53).

O conceito de geometria hidráulica foi apresentado por Leopold e Maddock $(1953)^{4}$ e, embora não mencionado por tais autores pode ser considerado como exemplo de sistema morfológico [...] A forma do canal é resposta que reflete no ajustamento aos débitos fluindo através de determinada secção transversal. Considerando que o canal em rios aluviais é resultante da ação exercida pelo fluxo sobre os materiais rochosos componentes do leito e das margens, pode-se afirmar que as suas dimensões serão controladas pelo equilíbrio entre as forças erosivas ${ }^{4}$ LEOPOLD, L.B.; MADDOCK JR, T. The hydraulic geometry of stream channels and some
physiographic implications. U.S. Geol. Survey Professional Paper, (252): $1-57,1953$. 


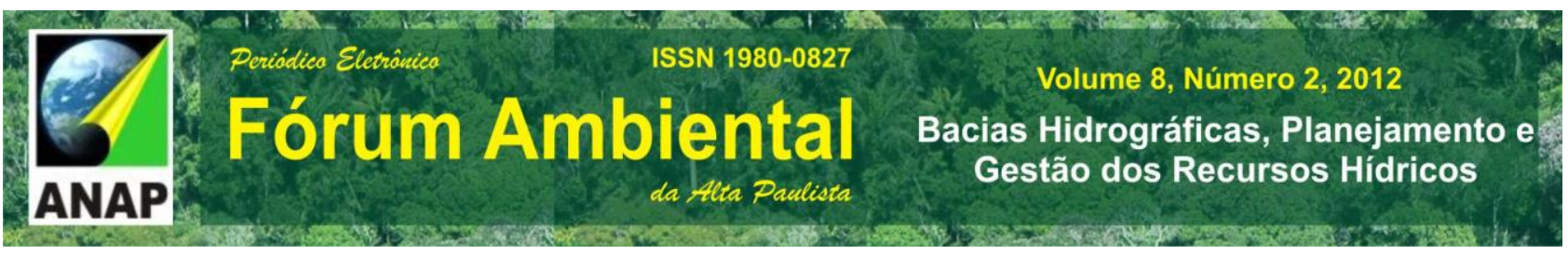

de entalhamento e os processos agradacionais depositando material no leito e em suas margens (CHRISTOFOLETTI, 1981, p. 53).

De acordo com Suguio (1937) a análise granulométrica dos sedimentos permite estabelecer uma expressão quantitativa da distribuição das partículas e grãos de acordo com seu diâmetro, tornando possível caracterizar e classificar os sedimentos, correlacionar sedimentos de áreas diferentes e deduzir a gênese destes. Neste contexto, Christofoletti (1981, p. 19), destaca que "o ambiente de sedimentação fluvial é importante para elucidar e interpretar a evolução histórica de paisagens na escala geológica”.

Além de uma perspectiva de análise das paisagens pretéritas, estudos ligados a sedimentologia abrangem ainda mudanças no comportamento dos processos fluviais, que refletem na qualidade e estabilidade dos ecossistemas aquáticos. Carvalho (1994), citado por Silva et al. (2004), ressalta que o conhecimento na área é importante em estudos ambientas ligados à flora e fauna aquática bem como no tratamento da água para abastecimento. Como destaca Elliot (1995), parafraseado por Silva et al. (2004), os sedimentos são, provavelmente, os mais significativos de todos os poluentes, por sua concentração, seus impactos no uso da água e seus efeitos no transporte de outros poluentes.

Do ponto de vista socioeconômico, Silva et al. (2004), consideram os estudos hidrossedimentológicos importantes para o Brasil, visto que os sistemas elétricos do país tem base predominantemente hidráulica. Projetos de barragens, captações e estações de tratamento de água, são diretamente influenciados pela presença de sedimentos na fonte hídrica (ROCHA, 2010).

\section{LOCALIZAÇÃo E CARACTERIZAÇÃo DA ÁREA DE ESTUDOS}

A área de estudo compreende as Bacias Hidrográficas dos Rios Aguapeí e Peixe, localizadas no oeste do Estado de São Paulo (figura 1). São Unidades Hidrográficas de Gerenciamento contíguas, as quais integram o Comitê de Bacias Hidrográficas dos Rios Aguapeí e Peixe (SIRGH, 2009, p. 32).

O Rio Aguapeí possui área de drenagem de $13.196 \mathrm{~km}^{2}$, limitando-se ao Norte com a Bacia do Rio Tietê, a Oeste com o Estado do Mato Grosso do Sul, tendo como divisa o 
Rio Paraná, a Leste seu limite é a Serra dos Agudos e ao Sul encontra-se com a Bacia do Rio do Peixe. Esta, por sua vez, possui área de drenagem de $10.769 \mathrm{~km}^{2}$, limitando-se com a Bacia do Rio Aguapeí ao Norte, ao Sul com a Bacia do Rio Paranapanema, a Oeste com o Rio Paraná e a Leste com a Serra dos Agudos e a Serra do Mirante (SIGRH, 2009).

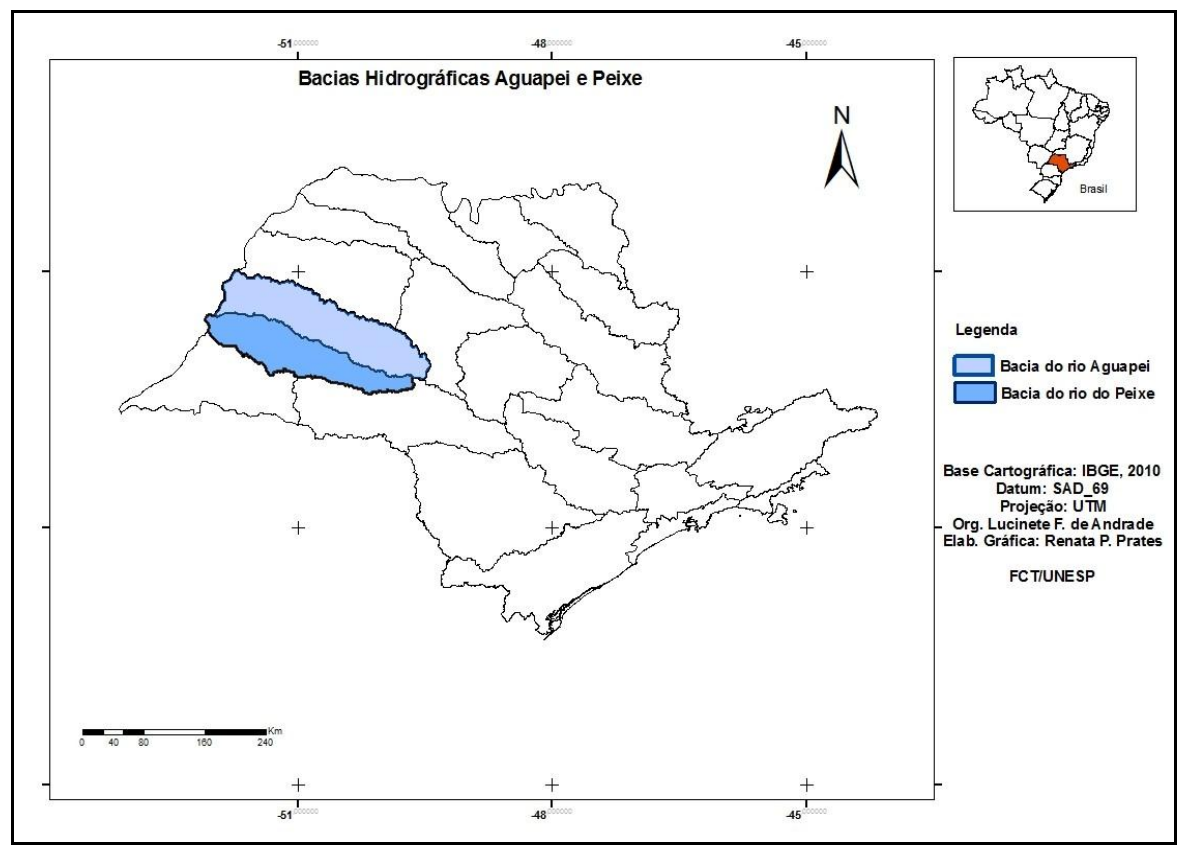

Figura 1 - Localização das Bacias Hidrográficas dos Rios Aguapeí e Peixe. Fonte: Andrade, 2010.

As bacias estão situadas geomorfologicamente sobre o Planalto Ocidental Paulista, que de acordo com o Mapeamento Geológico do Estado de São Paulo (IPT, 1981), está disposto sobre rochas do Grupo Bauru, este constituído por diversas formações predominantemente areníticas, em algumas regiões cimentadas por carbonato de cálcio. A região das bacias do Aguapeí e Peixe abrange principalmente a Formação Adamantina, que de acordo com Almeida (1996), tende a apresentar sedimentos mais finos e bem selecionados.

O Planalto Ocidental Paulista compreende um relevo levemente ondulado com predomínio de colinas amplas e baixas com topos aplainados (ROSS \& MOROZ, 1997). De acordo com Francisco (1989), em referência a Almeida (1964), a maior parte do Grupo Bauru encontra-se desfeito em relevo uniforme e monótono, com espigões de perfis 
convexos, configurando baixas e amplas colinas "que avançam em direção aos vales dos principais rios que buscam o Paraná, separando seus afluentes" (ALMEIDA, 1964 apud FRANCISCO, 1989, p. 50).

Referente as características pedológicas, Boin (2000), cita que os solos da região do Oeste Paulista tem sua gênese de rochas areníticas do Grupo Bauru e de rochas básicas do Grupo São Bento (Serra Geral). De acordo com Sudo (1980), sobre as colinas baixas e mais amplas próximas aos vales do Rio Paraná e à montante da cabeceira, ocorrem Latossolos Vermelho-Escuro.

O clima do Oeste Paulista é do tipo tropical, situado em uma área de transição climática, compartilhada pelos sistemas atmosféricos inter e extratropicais; nele ocorre conflito entre as massas Tropical Atlântica e Tropical Continental, e a massa Polar Atlântica, havendo ainda participação esporádica da massa Equatorial Continental (BOIN, 2000, p. 23). A área é caracterizada pela presença de um período seco no inverno e um período chuvoso durante o verão. De acordo com Boin (2000) a precipitação anual média varia entre 1200 e a 1500 mm, enquanto a temperatura média anual permanece acima de $22^{\circ} \mathrm{C}$.

De acordo com o Relatório da Situação das Bacias Hidrográficas do Aguapeí e Peixe (CBH-AP, 2011), o uso e ocupação do solo das bacias caracteriza-se principalmente por atividades agropecuárias. A Ocupação do Oeste Paulista teve início em meados dos anos 1920, no contexto de expansão cafeeira na região, seguido posteriormente pela cultura do algodão e a pecuária. O setor cafeeiro estimulou a expansão ferroviária, o que permitiu a fundação de municípios na região. De acordo com Nunes (2009, p. 29), a ferrovia estabeleceu uma relação econômica positiva com a via fluvial, tanto para transporte de gado, madeira, produtos agrícolas e mantimentos, quanto de deslocamento das pessoas; intensificando também a derrubada de mata e o cultivo agrícola, em meados do século $X X$.

A esta primeira alteração ambiental promovida pela colonização, sucederam-se outras alterações dentre as quais podem ser destacadas aquelas provocadas pelo processo de urbanização desde os anos de 1960; pela substituição das culturas agrícolas por outras e pela pecuária; pela construção de barragens de grande porte nos principais rios que delimitam o Planalto - o Grande, o Paraná e o Paranapanema - que transformaram seus principais cursos d'água em lagos 


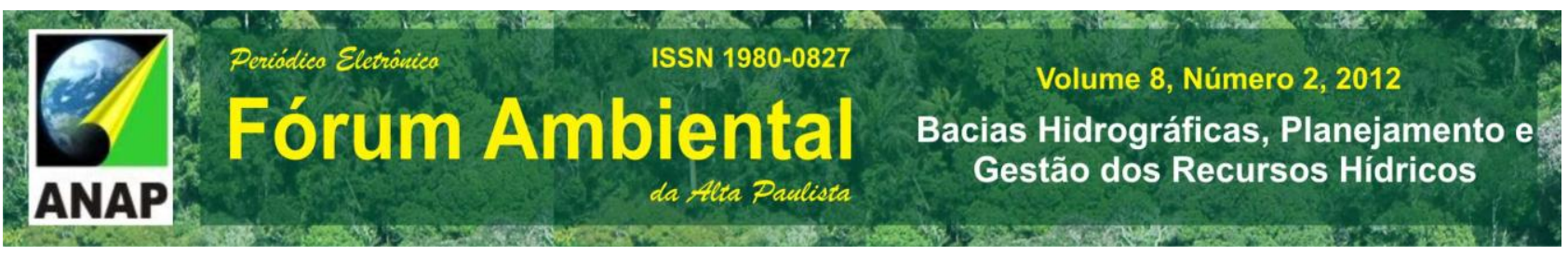

artificiais, durante os anos de 1960 a 1990 (DEAN, 1996 apud OLIVEIRA; BRANNSTROM, 2004).

Além da economia agropecuária, as bacias contam com atividades no setor de mineração, em alguns pontos de sua área. De acordo com o Relatório da Situação das Bacias Hidrográficas do Aguapeí e Peixe (2011), há a extração de areia e argila com expressividade nos municípios de Panorama e Paulicéia para o setor cerâmico, além de um porto de areia localizado em Tupã.

Considerando a importância ambiental e socioeconômica das bacias para os municípios que fazem parte de sua Região Hidrográfica, o trabalho se justifica por tratarse de um recurso relevante para a compreensão dos processos e dinâmicas que atuam em seus cursos fluviais, elementos estes que influem na estabilidade desses sistemas. Assim, o trabalho visa analisar o comportamento sedimentológico do leito dos rios Aguapeí e Peixe nos períodos pré e pós aguas altas, baseado numa análise espacial e temporal.

\section{MATERIAIS E MÉTODOS}

A coleta das amostras foi realizada em duas seções transversais dos Rios Aguapeí e do Peixe, com pontos de amostragem localizados a alto e a baixo curso dos canais. O levantamento dos dados foi realizado nos meses de dezembro de 2011 e junho de 2012, caracterizando períodos diferentes de acordo com o regime sazonal hidrológico/climático da região (período pré águas altas e pós águas altas).

Em campo, a coleta das amostras de carga de leito foi efetuada a partir de uma draga Van Veen, nas partes laterais e no talvegue do canal, nas seções. Posterior a coleta, as amostras foram levadas para o Laboratório de Geologia, Geomorfologia e Recursos Hídricos da FCT/UNESP para secagem. Após essa etapa, 100 gramas de sedimentos de cada amostra foram destorroadas com auxílio de um almofariz e pestilo. $\mathrm{Na}$ sequência, as alíquotas passaram por análise granulométrica por peneiramento, de acordo com a classificação proposta por Wentworth (1922).

O tratamento dos dados obtidos foi realizado por meio dos softwares Excel $e$ Granulo, em sua sistematização e para a geração de gráficos. A discussão dos dados foi 
realizada a partir de medidas estatísticas e o relacionamento entre as variáveis analisadas.

\section{RESULTADOS E DISCUSSÃO}

Para análise e discussão dos dados, foram utilizadas as medidas de frequência, grau de seleção, grau de assimetria e curtose das amostras. A tabela 1 contém a sitematização dos dados.

De acordo com Suguio (1973), o grau de seleção das amostras depende até certo ponto da granulometria do material, sendo melhor na areias e materiais mais grossos e decaindo nos sedimentos mais finos. Rocha (2011), em referência a Ponçano (1986), ressalta que o grau de seleção dos sedimentos reflete na variação das condições de fluxo na área deposicional. Considerando a escala proposta por Folk \& Ward, os sedimentos das seções dos Rios Aguapeí e Peixe classificam-se como moderadamente selecionados, em ambos os períodos de amostragem.

Tabela 1 - Dados do grau de seleção, grau de assimetria e curtose nas seções de amostragem

\begin{tabular}{ccccccc}
\hline \multicolumn{5}{c}{ Dezembro } & \multicolumn{3}{c}{ Junho } \\
& $\begin{array}{c}\text { Grau de } \\
\text { Seleção }\end{array}$ & $\begin{array}{c}\text { Grau de } \\
\text { Assimetria }\end{array}$ & Curtose & $\begin{array}{c}\text { Grau de } \\
\text { Seleção }\end{array}$ & $\begin{array}{c}\text { Grau de } \\
\text { Assimetria }\end{array}$ & Curtose \\
\hline $\begin{array}{c}\text { Alto curso do } \\
\text { Rio do Peixe } \\
\text { A baixo }\end{array}$ & 0,596 & $-0,003$ & 0,661 & 0,593 & $-0,058$ & 0,902 \\
$\begin{array}{c}\text { curso do Rio } \\
\text { do Peixe }\end{array}$ & 0,542 & $-0,064$ & 0,82 & 0,553 & $-0,161$ & 0,88 \\
$\begin{array}{c}\text { Alto curso do } \\
\text { Rio Aguapeí } \\
\text { A baixo }\end{array}$ & 0,51 & 0,168 & 1,058 & 0,52 & $-0,017$ & 0,939 \\
curso do Rio & 0,631 & $-0,0503$ & 1,009 & 0,609 & $-0,063$ & 0,836 \\
Aguapeí & & & & & & \\
\hline
\end{tabular}

Fonte: Dados obtidos em campo. 


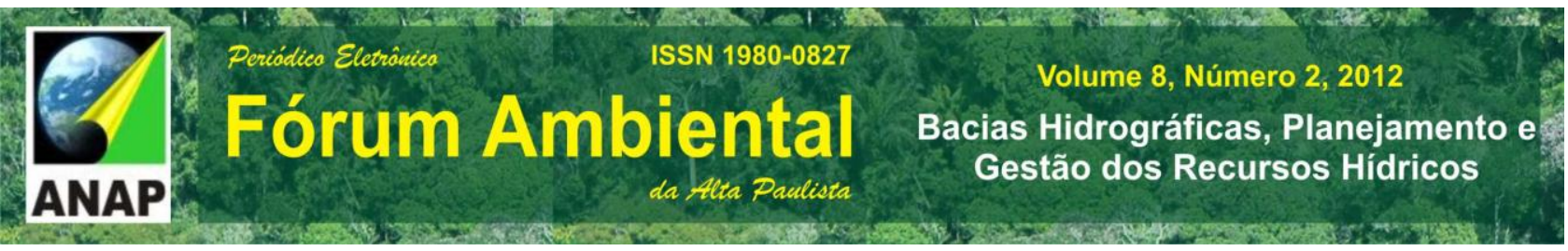

Segundo Almeida e Rocha (2004) o grau de assimetria consiste na tendência dos dados se dispersarem de um lado ou outro da média. O parâmetro pode variar à direita ou a esquerda do diâmetro médio, configurando-se em positivo ou negativo. Duane (1964) citado por Queiroz e Rocha (2010), aponta que a assimetria negativa indica áreas de remoção seletiva e a assimetria positiva, áreas de deposição.

Suguio (1973), cita que se os resultados forem positivos a amostra possui uma cauda de material mais fino; se os valores forem negativos, a cauda estará do lado dos materiais mais grosseiros. A partir dos dados obtidos, verifica-se que as amostras dos cursos possuem assimetria muito negativa, segundo a proposta de Folk \& Ward para o Grau de Assimetria. Neste sentido, considera-se que as amostras dos Rios Aguapeí e Peixe, nos meses de dezembro e junho, possuem uma cauda de material mais grosseiro.

No que se refere a curtose, de acordo com a escala proposta por Folk \& Ward, as amostras podem classificar-se em: muito platicúrtica, platicúrtica, mesocúrtica, leptocúrtica, muito leptocúrtica e extremamente leptocúrtica. A curtose é uma medida que retrata o grau de agudez dos picos nas curvas de distribuição de frequência (SUGUIO, 1973). Rocha (2011), destaca que esta medida pode ser utilizada como parâmetro na diferenciação de ambientes, sugerindo a existência de processos atuantes na mudança das caudas de distribuição. Ponçano (1986), referenciado por Queiroz e Rocha (2010), considera que as distribuições leptocúrticas poderiam indicar remoção de uma fração dos sedimentos por meio de correntes de fundo enquanto as distribuições platicúrticas poderiam indicar mistura de populações diferentes.

De acordo com os resultados, as amostras do Rio do Peixe, apresentam-se como platicúrtica, exceto pela seção a alto curso, no mês de junho, que se classifica como mesocúrtica; indicando, ainda assim, que as amostras encontram-se com as modas amplamente separadas. O Rio Aguapeí também apresenta amostras com classificação mesocúrtica em suas seções, em ambos os períodos de coleta dos dados.

Além das medidas de grau de seleção, grau de assimetria e curtose, os dados de frequência das amostras também foram analisados. Os gráficos abaixo (figura 2) demonstram a distribuição das classes granulométricas em ambos os canais, no período de dezembro. 

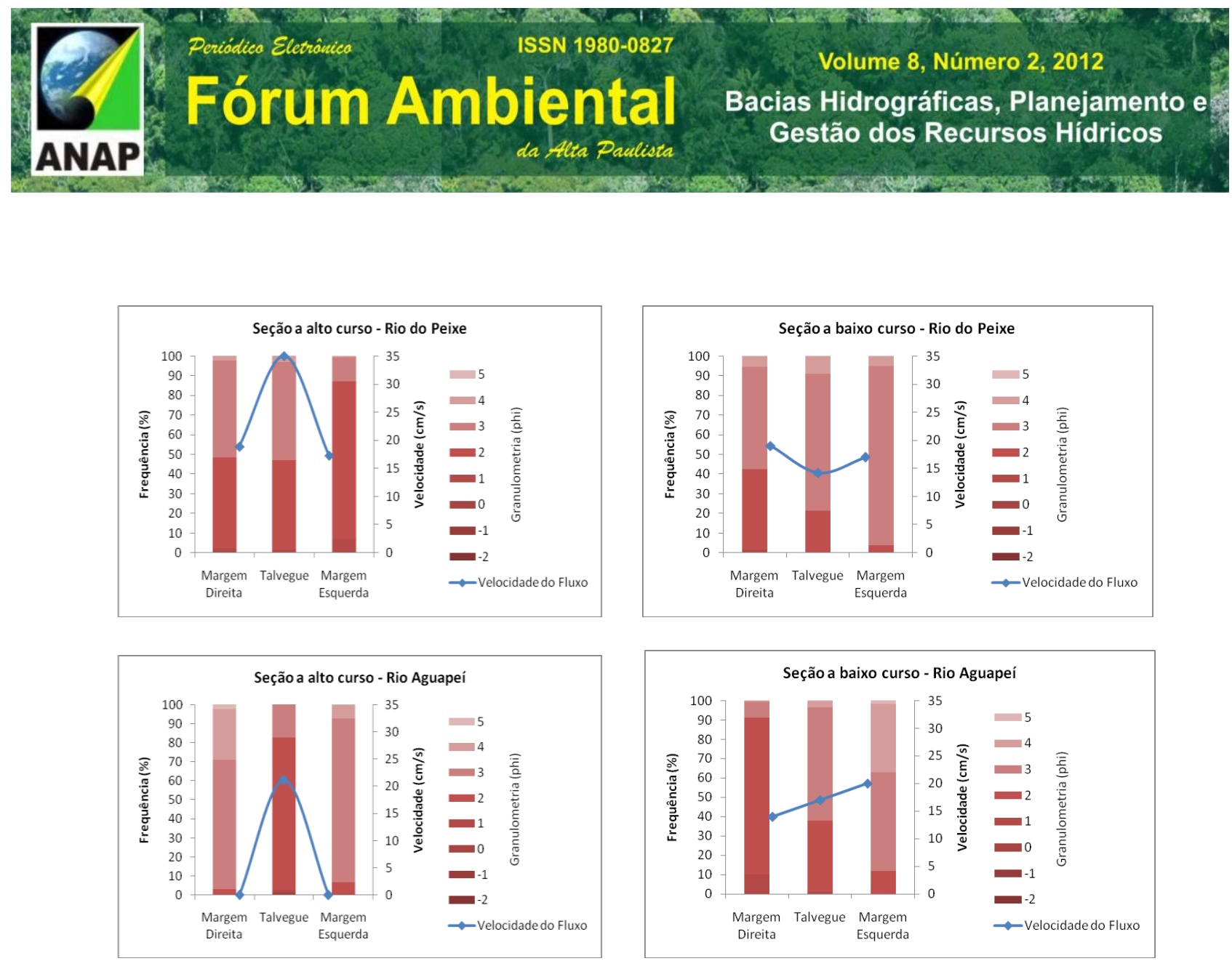

Figura 2 - Distribuição Granulométrica dos sedimentos nos Rios Aguapeí e Peixe, no período de dezembro de 2011.

Em análise aos dados de dezembro de 2011, nota-se que na seção a alto curso do Rio do Peixe há predominância das classes granulométricas areia média e areia fina, tendo a margem esquerda apresentado maior concentração de areia média. Na seção a alto curso do Rio Aguapeí também predominam as classes areia média e areia fina. Observa-se, no entanto, que a concentração de sedimentos de areia média encontra-se principalmente nas margens do canal, diferente do talvegue que possui maior ocorrência de areia fina.

Na seção a baixo curso do Rio do Peixe há maior concentração de areia fina. Na seção equivalente do Rio Aguapeí, observa-se a concentração de areia média na margem direita, diferente dos outros pontos que possuem maior ocorrência de sedimentos de classe granulométrica areia fina.

No período de junho, as seções a alto curso de ambos os canais apresentam maior concentração de sedimentos de areia fina, com exceção das margens esquerdas, 
nas quais ocorrem sedimentos de classe granulométrica areia média com maior frequência, como pode ser observado na figura 3 :
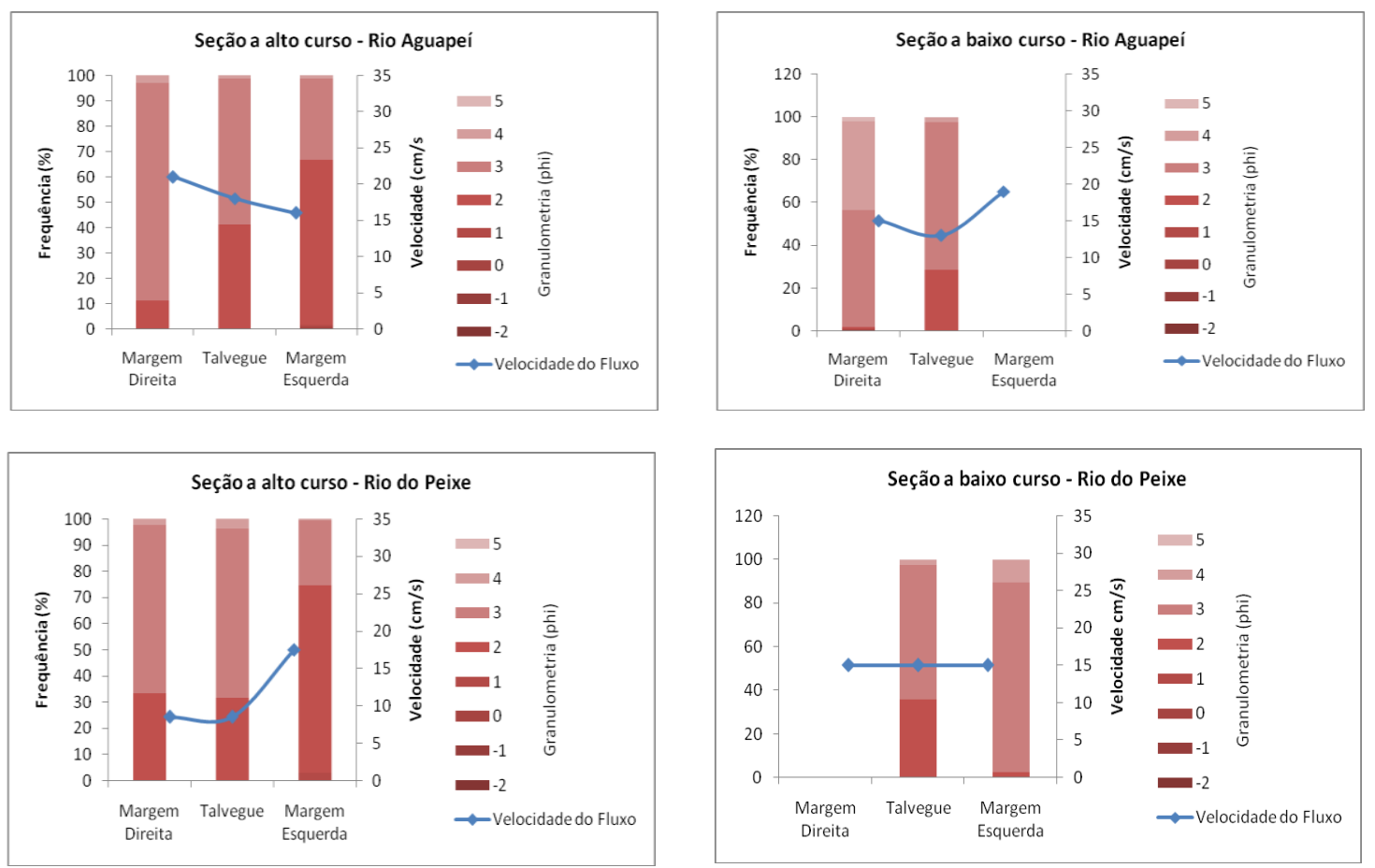

Figura 3 - Distribuição Granulométrica dos sedimentos nos Rios Aguapeí e Peixe, no período de junho de 2012.

Na seção a baixo curso do Rio do Peixe há o predomínio da classe areia média. $\mathrm{Na}$ seção adjacente do Rio Aguapeí ocorre o mesmo, se diferenciando, no entanto, por uma concentração significativa de sedimentos da classe granulométrica areia muito fina na margem direita. Cabe citar que, não foi possível realizar a coleta de sedimentos na margem direita na seção a baixo curso do Rio do Peixe, bem como a margem esquerda da seção a baixo curso do Rio Aguapeí, devido a impedimentos do método utilizado.

Com relação a velocidade do fluxo, verifica-se que os pontos com maiores valores apresentam variação nas classes granulométricas dos sedimentos depositados no leito, sendo mais evidente no mês de dezembro, caracterizado como período pré águas altas.

Em uma análise ampla, verifica-se que no mês de dezembro no canal do Rio do Peixe as classes granulométricas decresceram em direção jusante. Já no Rio Aguapeí 
observa-se não é evidente e observa-se uma uniformidade na distribuição dos sedimentos nas duas seções amostradas.

No mês de junho, período que pode ser considerado como pós águas altas, as classes granulométricas da margem esquerda nas seções do Rio do Peixe diminuíram no sentido jusante. Já o talvegue teve pouca variação nas duas seções monitoradas. No rio Aguapeí as dimensões dos sedimentos decresceram da seção à montante para a jusante. O afinamento do calibre dos sedimentos é evidenciado na literatura, como citado por Bigarella e Suguio (1979), que nos cursos d'água ocorre um aumento da relação larguraprofundidade à jusante assim como uma diminuição de declividade, o que resulta em uma diminuição na competência do rio.

\section{CONSIDERAÇÕES FINAIS}

A partir da análise dos dados de frequência, verificou-se que nos Rio Aguapeí e Peixe houve um predomínio das classes granulométricas de areia média e areia fina nas seções e períodos amostrados, o que pode ser associado ao substrato geológico da região de estudos.

As medidas de grau de seleção, grau de assimetria e curtose demonstram que os sedimentos nas seções de ambos os rios são moderadamente selecionados, apresentam uma assimetria muito negativa e o predomínio de curtose mesócurtica. O parâmetro de assimetria pode indicar o predomínio de processos de remoção seletiva nos pontos de amostragem, que, no caso da seção a alto curso do Rio do Peixe, está associada a mistura de sedimentos de classes diferentes (curtose platicúrtica).

E geral a distribuição dos materiais tiveram menor variabilidade na distribuição granulométrica no período pós águas altas, no mês de junho, enquanto foi possível observar que no mês de dezembro, pré águas altas, há maior variação de distribuição espacial, com afinamento no sentindo jusante do canal.

\section{REFERÊNCIAS BIBLIOGRÁFICAS}


ALMEIDA, B. T.; ROCHA, P. C. Dinâmica sedimentológica do ribeirão Palmito - Três Lagoas-MS-Brasil. In: I Encontro Sul-Americano de Geomorfologia, 2004, Santa MariaRS. Anais de trabalhos completos, 2004.

BIGARELLA, J. J; SUGUIO, K. Ambiente fluvial. Curitiba, Editora Universidade Federal do Paraná e Associação de Defesa e Educação Ambiental, 1979. 172 p.

BOIN, M. N. Chuvas e Erosões no Oeste Paulista: Uma análise Climatológica Aplicada. Tese (Doutorado em Geografia). IGCE - UNESP, Rio Claro, 2000.

BOTELHO, R. G. M.; SILVA, A. S. da. Bacia Hidrográfica e Qualidade Ambiental. In: VITTE, A. C.; GUERRA, A. J. T. Reflexões Sobre a Geografia Física no Brasil. Rio de Janeiro: Bertrand Brasil, 2004. p. 153-192.

CBH-AP. Relatório da Situação das Bacias Hidrográficas dos Rios Aguapeí e Peixe. Disponível em: <http://www.comiteap.sp.gov.br/file/Relatorio_Situacao_2011CBH_AP.zip>. Acesso em: 27. AGO. 2012.

CHRISTOFOLETTI, A. Geomorfologia fluvial. São Paulo: Editora Edgard Blucher Ltda, 1981. $296 \mathrm{p}$.

CUNHA, S. B. da. Geomorfologia fluvial. In: GUERRA, A. J. T.; CUNHA, B da. Geomorfologia: uma atualização de bases e conceitos. 4. ed., Rio de Janeiro: Bertrand Brasil, 1994. 211-252 p.

DURLO, M. A; SUTILI, F. J. Bioengenharia: manejo biotécnico de cursos de água. Porto Alegre: EST edições, 2005. 189 p.

QUEIROZ, F. L. L.; ROCHA, P. C. Avaliação de Sedimentos do Leito no Canal Curutuba - Planície Fluvial do Alto Rio Paraná, Mato Grosso do Sul, Brasil. Revista Eletrônica da Associação dos Geógrafos Brasileiros, Seção Três Lagoas, v. 07, p. 147164, 2010.

NOVO, E. M. L. de M. Ambientes Fluviais. In: FLORENZANO, T. G. Geomorfologia: conceitos e tecnologias atuais. São Paulo: Oficina de Textos, 2008, 219-246 p.

INSTITUTO DE PESQUISAS TECNOLÓGICAS DO ESTADO DE SÃO PAULO - IPT. Mapa geológico do Estado de São Paulo. Escala 1:500.000. Publicação IPT no. 1.184. São Paulo, 1981a. 2v.

NASCIMENTO, W M do; VILLAÇA, M. G. Bacias Hidrográficas: planejamento e gerenciamento. Revista Eletrônica da Associação dos Geógrafos Brasileiros, Seção Três Lagoas, v. 1 N 7, p. 102-120, 2008. 
NUNES, A. B. Inventário do Patrimônio Industrial: a estação ferroviária de Presidente Epitácio. 2009. TCC (Graduação em Turismo) - Campus Experimental de Rosana, Universidade Estadual Paulista, Rosana.

OLIVEIRA, A. M. S.; BRANNSTROM, C. Fundamentos da história ambiental do Planalto Ocidental do Estado de São Paulo. In: Anais Eletrônicos II Encontro Estadual de História ANPUH-BA. Feira de Santana, 2004.

ROCHA, P. C. Variação espaço-temporal dos sedimentos do leito em canais da planície fluvial do Alto Rio Paraná, Centro-Sul do Brasil. In: VIII Simpósio Nacional de Geomorfologia, 2010, Recife. Anais do VIII Simpósio Nacional de Geomorfologia, 2010.

ROCHA, P. C. Avaliação do transporte de sedimentos no rio Santo Anastácio e processos de aporte. In: Anais do IX ENANPEGE, 2011. Goiânia.

ROSS, J.L.S. \& MOROZ, I.C. Mapa Geomorfológico do Estado de São Paulo. São Paulo: Laboratório de Geomorfologia Depto de Geografia FFLCH-USP/Laboratório de Cartografia Geotécnica - Geologia Aplicada - IPT/FAPESP, 1997. 63p.

ROSS, J. L. S. Geomorfologia Ambiental. In: Antonio Teixeira Guerra; Sandra B. da Cunha. (Org.). Geomorfologia Ambiental. Rio de janeiro: Bertrand, 1998, p. 351-387.

SIGRH. Relatório da Situação das Bacias Hidrográficas dos Rios Aguapeí e Peixe. Disponível em: <http://www.sigrh.sp.gov.br/sigrh/basecon/relatoriosituacao2009/2_aguapeipeixe.pdf>. Acesso em: 15. ABRIL. 2012.

SILVA, A. M.; SHULTZ, H. E.; CAMARGO, P. B. Erosão e Hidrossedimentologia em Bacias Hidrográficas. São Carlos: RiMa, 2004.

SUDO, H. Bacia do Alto Santo Anastácio: estudo geomorfológico. São Paulo, 1980. 235p. Tese (Doutorado em Geografia Física com ênfase em Geomorfologia) FFLCH/USP.

SUGUIO, K. Introdução a sedimentologia. São Paulo: Edgard Blucher, 1973. 